\title{
OJS

\section{CANÇÕES LIBERTÁRIAS NO ENSINO: A COMPREENSÃO DO SERTÃO NORDESTINO NA GEOGRAFIA ESCOLAR}

\author{
Léon Denis Ferreira Xavier ${ }^{1}$, Christian Dennys Monteiro de Oliveira ${ }^{2}$
}

\begin{abstract}
${ }^{1}$ Mestrando do Programa de Pós-Graduação Integração da América Latina, vinculado a Universidade de São Paulo (USP) e Licenciado em Geografia pela Universidade Federal do Ceará (UFC). E-mail: leon.profgeografia@gmail.com. ORCID: https://orcid.org/0000-0002-1743-7685

2 Professor do Programa de Pós-Graduação em Geografia da Universidade Federal do Ceará (UFC). E-mail: cdennys@gmail.com. ORCID: http://orcid.org/0000-0001-8025-2045.
\end{abstract}

Artigo recebido em 06/11/2020 e aceito em 15/03/2021

\begin{abstract}
RESUMO
O presente trabalho tem origem em um projeto de licenciatura em Geografia, como foco na perspectiva das artes como leitura das paisagens patrimoniais latino-americanas. Baseando-se em alguns princípios das abordagens libertárias e fenomenológicas da geografia escolar para entender o poder do sujeito nas suas ações cotidianas, apropriou-se de uma ferramenta artística, a canção musical, ainda considerada "alternativa" no ensino básico. O conteúdo trabalhado por meio da intervenção em sala de aula foi o Sertão Nordestino. E as canções foram selecionadas por contraste associativo (tradicional X não usual). Tendo em vista que arte música é portadora de uma geograficidade, buscou-se compreender a paisagem sertaneja como compreensão de um mundo vivido, sem engessamentos formais e acessível ao educando. $\mathrm{O}$ resultado da reflexão proposta demonstra possibilidade musical em sala de aula, como estratégia fácil e competente na compreensão de conteúdos geográficos.
\end{abstract}

Palavras-chave: Arte musical. ferramentas de ensino, abordagens libertárias, paisagem sertaneja

\section{LIBERTARY SONGS IN TEACHING: UNDERSTANDING THE "SERTÃO NORDESTINO” IN SCHOOL GEOGRAPHY}

\begin{abstract}
The present work originates from a degree project in Geography, focusing on the perspective of the arts as a reading of Latin American heritage landscapes. Based on some principles of libertarian and phenomenological approaches of school geography to understand the subject's power in his daily actions, he appropriated an artistic tool, the musical song, still considered "alternative" in basic education. The content worked through the classroom intervention was Sertão Nordestino. And the songs were selected by associative contrast (traditional X unusual). Bearing in mind that art music is a carrier of geography, we sought to understand the country landscape as an understanding of a lived world, without formal plasterings and accessible to the student. The result of the proposed reflection demonstrates musical possibility in the classroom, as an easy and competent strategy for understanding geographic content.
\end{abstract}

Keywords: Musical art. teaching tools, libertarian approaches, country landscape 


\title{
CANCIONES LIBERTARIAS EN EL ENSEÑANZA: LA COMPRENSIÓN DEL “SERTÃO NORDESTINO” EN LA GEOGRAFÍA ESCOLAR.
}

\begin{abstract}
RESUMÉN
El presente trabajo tiene su origen en un proyecto de grado en Geografía, centrado en la perspectiva de las artes como lectura de los paisajes patrimoniales latinoamericanos. Partiendo de unos principios de enfoques libertarios y fenomenológicos de la geografía escolar para comprender el poder del sujeto en sus acciones cotidianas, se apropió de una herramienta artística, el canto musical, todavía considerado "alternativo" en la educación básica. El contenido trabajado a través de la intervención en el aula fue Sertão Nordestino. Y las canciones fueron seleccionadas por contraste asociativo (tradicional X inusual). Teniendo en cuenta que la música artística es portadora de la geografía, buscamos entender el paisaje campestre como una comprensión de un mundo vivido, sin enlucidos formales y accesible al alumno. El resultado de la reflexión propuesta demuestra la posibilidad musical en el aula, como una estrategia fácil y competente para comprender el contenido geográfico.
\end{abstract}

Palabras clave: Arte musical. herramientas de enseñanza, enfoques libertarios, paisaje rural

\section{INTRODUÇÃO}

A música, como poética popular e linguagem artística, convertesse em canção (tradicional e moderna) povoando nossa cultura de audições desde berço. A criança, em formação pré-escolar, se alimenta da linguagem e das paisagens musicais que a envolve, como um reservatório de identificações. Justamente por constituir mínimas harmonias e ordenamentos sensoriais em um oceano caótico de sons, silêncios e barulhos. Nascemos com e crescemos com música. E formamos nossa espacialidade existencial por seu intermédio. Espacialidade e identificação no e com o mundo. Conforme o jornalista Joachim-Ernest Berendt, a música forja o universo da consciência mediante a ideia de que tanto o mundo quanto os deuses interagem no som... Nada Brahma (BERENDT, 1997). Então... por que a ciência escolar dos espaços - a Geografia Escolar - e suas categorias de representação, tanto distanciou da linguagem musical?

Considerando a forma de como sistema escolar - e, consequentemente, as aulas de geografia - está organizada não corresponde a uma ação dominantemente "inclusiva" para todos os estudantes, a alta seletividade impede as aprendizagens essenciais do mundo vivido. Pelos hábitos, a Escola continua tratando a criança e os jovens mais como simples depósitos de conhecimentos padronizados, no esquema da "educação bancária" proposta por Freire (1996), e menos como produtores existenciais desses saberes. Se faz necessário a busca pela inclusão de todos os aprendizes em outro nível de equilíbrio. E a musicalidade, linguagem e paisagem geográfica nos pode apontar esse "outro nível". Cabe-nos utilizar diferentes métodos para facilitar o processo de 
aprendizagem, visto que os estudantes já possuem acesso a informação através da tecnologia disposta atualmente, e considerar as individualidades de cada estudante sua experiência ancestral e das vivências da primeira infância.

A vastidão da ciência geográfica permite que se usem diferentes recursos para seu estudo, pois como posto por Souza (2018) no pensamento libertário a geografia é uma ciência mais sincrética que sintética por se aprofundar nas discussões dos aspectos físicos e sociais, construindo não só a síntese, mas podendo produzir uma outro ponto de vista do conhecimento compreendendo as relações existentes entre a sociedade e o espaço enquanto objeto de estudo. Um bom exemplo disso é a clássica afirmação de Reclus (1905-1908, v.1, p.4) em que conclui que o homem "é a natureza tomando consciência de si mesma". Afinal, esta concepção possibilita compreender o ser humano como um componente do meio, sendo a partir daí a construção do conhecimento e tendo por base as relações entre homem e espaço. O que possibilita uma maior ciência dos impactos das atitudes humanas na natureza natural e na sua própria natureza humanizada; hoje emergente desde a infância na cultura escolar.

Além disso, a extensão da ciência geográfica permite que conheçamos o mundo a partir de expressões artísticas, como deixa claro o conceito de geograficidade, aplicado de forma geral à literatura, à pintura à música, pois ela se trata "uma geografia vivida em ato, que tem na experiência o principal caminho de construção do conhecimento" (MARANDOLA JR; OLIVEIRA, 2009, p.494). O que está colocado naquela forma de expressão pode conter múltiplos aspectos geográficos por se tratar de uma espécie de relato da percepção individual ou coletiva do mundo ao seu redor; e simultaneamente em seu interior. Uma geograficidade reúne, em extensão e profundidade as geografias convencionais separam. Desta forma, a música que religa polos espaço-existenciais, pode ser compreendida como uma das várias formas de se representar o espaço que se conhece (XAVIER 2019b).

A partir disso é pensada a utilização da música como uma ferramenta que possibilite a construção dos conhecimentos geográficos, pois como posto por Ferreira (2002, p. 13), “com a música é possível ainda despertar e desenvolver nos alunos sensibilidades mais aguçadas na observação de questões próprias à disciplina alvo". Desta forma e reconhecendo que a música pode apresentar uma descrição do espaço, assim esta se torna um potente aliado para o ensino de Geografia. 
Com base no exposto, surge a proposição de se trabalhar algumas músicas populares; dentre elas, canções com ritmos considerados tradicionais, mas também ritmos mais jovens para se analisar a diferenciação na concepção do espaço destas expressões. O que permite também compreender/projetar as bases do conhecimento da paisagem sertaneja do Nordeste brasileiro, tendo noção de que esta concepção do conjunto regional, de certa forma, se distancia do humanismo libertário e das variantes fenomenológicas do ser sertanejo. Porém possibilita uma reflexão sobre o pertencimento e o imaginário, do que se esconde e se revela nos valores existenciais indispensáveis à identidade dessa paisagem.

Desta forma, o presente artigo busca expor e contribuir para a discussão da utilização da poética musical, aqui chamada pelo termo canção popular em sua busca libertária (uma canção libertária?) como uma ferramenta do ensino para aprendizagem de geografia. Tendo por base algumas proposições da ação libertária na experiência de potencialização da aprendizagem; o que favorável restauração da parceria de saberes musicais e geográficos pela de geograficidade das canções. O fundamental é considerar esse "restauro" nos limites efetivo da experimentação docente; justamente porque o estudo tanto emerge da formação inicial da licenciatura em geografia quanto se destina a ser reinventado em novas práticas docentes, com outras musicalidades, linguagens e paisagens geográfica trabalhadas no ensino básico.

\section{CAMINHOS TEÓRICO-METODOLÓGICOS}

Para cumprir com o proposto é preciso que sejam colocados os conceitos e as temáticas que baseiam as ideias trabalhadas. Em um primeiro momento é importante construirmos a relação entre a geografia e a música para que seja possível discutir seu uso em sala de aula, em seguida a associação entre conceitos humanistas e a expressão musical, sendo ambas as discussões permeadas pelos ideais libertários trabalhados.

Considerando como posto por Xavier (2019a) a música trabalha, por vezes, a descrição das paisagens, ou situações que podem possuir um valor para a Geografia, Silva (2015) afirma ainda que algumas temáticas da ciência geográficas podem ser presentes nas músicas, como o lugar, a paisagem, questões migratórias e a própria política. Além disso, podemos considerar também que a música é capaz de "nos transportar para lugares que somente os caminhos da nossa mente conhecem" (OLIVEIRA E HOLGADO, 2016) e entender como ela está diretamente relacionada 
com nossa subjetividade, sendo capaz de possibilitar uma atualização da nossa percepção de mundo, ao conhecermos outras formas de vê-lo, neste caso, a dos autores da música.

A música se trata de uma expressão artística, que em geral, aborda a forma como o artista enxerga o mundo, sendo colocada através de metáforas ou de maneira mais direta, por isso podemos compreendê-la como possuidora de geograficidade, visto que ela possui na experiência individual sua base, tal qual proposto por Marandola Jr e Oliveira (2009). Assim, podemos entender as obras musicais através do conceito de Lugar como visto na abordagem humanista, em que ele é "um mundo de significado organizado" (TUAN, 1983, p. 198) "onde cada um de nós se relaciona com o mundo" (RELPH, 2012) e considerando que a música pode expressar a visão não só individual, mas indiretamente coletiva a partir das construções sociais vividas no espaço, desta forma podemos entender o lugar como proposto por Lowenthal (1961), sendo ele a visão compartilhada por um grupo do/no mundo.

Torna-se possível assim encontrar em meio às expressões musicais os aspectos geográficos mais internos, além disso, reconhecer que "a Geografia Humanística é antes de tudo uma geografia que liberta" (PIZOTTI, 2016, p. 105) por empossar o homem, ao levar em conta suas experiências, possibilita uma análise e compreensão de mundo mais próxima a perspectiva libertária que, na sistematização da Pedagogia Libertária de Lipiansky (2007), acredita-se no conhecimento do mundo na sua totalidade, para que se torne possível a plena liberdade do homem reconhecendo também o poder de suas ações sobre o espaço.

Além disso, é possível através da música, assim como por outros recursos, entrar em contato com o conhecimento prévio do estudante, incluindo este no processo de construção do próprio saber, possibilitando que este se sinta confortável no ambiente escolar, como colocado por Oliveira e Holgado (2016) que afirmam ser necessário pensar um ensino em que o aluno encontre sua identidade, pois como é colocado por Kaercher (2011, p. 208), muitos estudantes não veem mais sentido nas aulas de Geografia por elas estarem distante da sua realidade. Oliveira (1998), assim como Kropotkin (1885), afirma também que a ciência geográfica, deve ser mais próxima dos estudantes, inclusive pela sua relação com o cotidiano e a possibilidade de construção de afeição pela natureza.

Por fim é possível conceber que a música, como uma ferramenta de ensino de Geografia, é uma valorosa aliada em sala de aula ao permitir que, além dos estudantes se sentirem mais 
próximos da ciência, possam compreender a partir dela o espaço de uma maneira crítica e do ponto de vista de quem está diretamente em contato com este.

\section{COMPREENDENDO O ESPAÇO SERTANEJO ATRAVÉS DA MÚSICA}

Compreendendo que a formação geográfica de um indivíduo está além daquela geografia que é vista em sala de aula, como bem coloca Oliveira (2008) afirmando a apreensão desta pelos meios de comunicação tendo como exemplo a ferramenta jornalística, podemos afirmar que é possível entender a música como uma ferramenta de comunicação que tem a possibilidade de transmitir um conhecimento geográfico. Assim é possível compreender que a música, enquanto um símbolo por carregar significados e informações, permite que conheçamos e formemos imagens mentais sobre o mundo que conhecemos ou não.

De acordo com Elíade (1979) os símbolos estão presentes na sociedade humana desde os tempos mais longínquos e, a partir disto, conclui-se que o simbolismo é inerente ao homem e pode estar relacionado a idealizações. Desta forma podemos entender a música como uma linguagem poética capaz de projetar uma experiência visual, além da auditiva, que nos permite relacionar imagem e som, ao menos no campo imaginário, ainda que de forma idealizada ou estereotipada pelas informações que são recebidas pelos meios de comunicação e não interpretados de maneira crítica.

Já considerando que a canção musical pode ser portadora de uma geograficidade (seja do autor o do contexto de sua criação/execução), é possível que possamos compreender melhor as categorias espaciais através delas; seja por uma leitura simples do seu texto e sonoridade, ou mesmo buscando encontrar metáforas que possam traduzir de maneira poética o ambiente em que o artista está inserido. Ao estudarmos o semiárido nordestino, buscamos algumas músicas consideradas marcantes na capacidade de representação regional, falam tanto direta quanto metaforicamente das paisagens em sua contextualização física e social da realidade envolvente. São elas Asa Branca (composta por Luiz Gonzaga e Humberto Teixeira) e A Volta da Asa Branca (composição de Luiz Gonzaga e Zé Dantas). Já na representação menos tradicional e mais jovem do mesmo contexto regional, a canção utilizada foi Norte, Nordeste Me Veste (composição autoral de Rapadura), do conjunto Rap. 
Nestas canções podemos observar alguns fatores que nos remetem imaginário densamente nordestino. Não só em suas letras, mas na sonoridade instrumental (arranjos e ritmos), com os efeitos sonoros que estão postos - mais especificamente na última - trazendo introdução e interlúdio composta pela declamação de uma poesia de Patativa do Assaré. As composições permitem-nos observar um contraste entre o que é posto como o tradicional e o moderno, desde as sonoridades, as letras e as formas de expressão, pois apesar destas diferenciações o "objeto" delas é o mesmo, o espaço do Nordeste, em específico do Semiárido.

A sonoridade pode também nos remontar ao espaço, tendo como exemplo, o "choro" (formato sonoro associado a um lamento) da sanfona, na música Asa Branca de Luiz Gonzaga que passa uma sensação de tristeza ao observar a paisagem seca que é retratada e isto diz respeito a forma como o sertanejo vê o espaço durante este período da ausência das chuvas, podendo também ser uma forma de compreender, através do sentimento e da audição, como está posta a relação entre homem e espaço. Isso posto, podemos assimilar alguns trechos das músicas com o conhecimento que se tem sobre o espaço, tendo por início partes de Asa Branca.

\section{FIGURA 1: LETRA DA MÚSICA “ASA BRANCA”}

\section{Asa Branca}

Luiz Gonzaga, 1947

Quando olhei a terra ardendo

Qual fogueira de São João

Eu perguntei a Deus do céu, ai

Por que tamanha judiação

Eu perguntei a Deus do céu, ai

Por que tamanha judiação

Que braseiro, que fornaia

Nem um pé de prantação

Por falta d'água perdi meu gado

Morreu de sede meu alazão

\section{$[\ldots]$}

Espero a chuva cair de novo

Pra mim voltar pro meu sertão

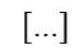

Inté mesmo a asa branca

Bateu asas do sertão Então eu disse, adeus Rosinha Guarda contigo meu coração

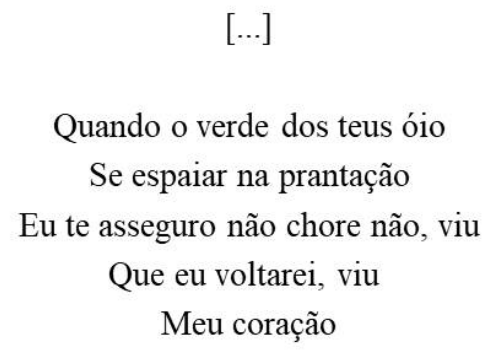

Elaboração: Autor, 2020

Xavier e Oliveira, 2021

ISSN 2594-9616 
Nas duas primeiras estrofes percebemos que Luiz fala da seca, ao citar a "terra ardendo" e a morte do seu alazão junto a de seu gado, devido a falta d'água, e demonstra a religiosidade, um importante ponto na construção da imagem que normalmente se tem do nordestino sertanejo através da comparação da terra a fogueira da festa de São João, onde é possível observar a religião perpassando a cultura dos habitantes do semiárido, e do questionamento ao deus em que se acredita sobre a situação.

Apesar de questionar a seca, o eu-lírico reconhece que se trata de um ciclo e que em breve a chuva pode aparecer e permitir sua volta para sua terra de origem através da metáfora "Quanto $o$ verde dos teus óio / Se espaiar na prantação" e da colocação direta "Espero a chuva cair de novo / Pra mim voltar pro meu sertão", pois reconhece na primeira que com o retorno das chuvas a vegetação semiárida rapidamente ganha a cor verde, assim como os olhos de sua amada. Desta forma, em uma curta música está descrito um pouco sobre o espaço físico do semiárido nordestino, seus fenômenos climáticos e sociais, como a migração de retorno.

Como uma continuidade desta faixa, podemos compreender novamente o conhecimento de Luiz Gonzaga sobre os aspectos naturais que estão colocados na letra da música A Volta da Asa Branca.

FIGURA 2: LETRA DE “A VOLTA DA ASA BRANCA”

\begin{tabular}{cc}
\multicolumn{2}{c}{ Asa Branca } \\
Luiz Gonzaga, & 1947 \\
Quando olhei a terra ardendo & Espero a chuva cair de novo \\
Qual fogueira de São João & Pra mim voltar pro meu sertão \\
Eu perguntei a Deus do céu, ai & {$[\ldots]$} \\
Por que tamanha judiação & Inté mesmo a asa branca \\
Eu perguntei a Deus do céu, ai & Bateu asas do sertão \\
Por que tamanha judiação & Então eu disse, adeus Rosinha \\
& Guarda contigo meu coração \\
Que braseiro, que fornaia & {$[\ldots]$} \\
Nem um pé de prantação & Quando o verde dos teus óio \\
Por falta d'água perdi meu gado & Se espaiar na prantação \\
Morreu de sede meu alazão & Eu te asseguro não chore não, viu \\
{$[\ldots]$} & Que eu voltarei, viu
\end{tabular}

Elaboração: Autor, 2020 
Aqui é possível perceber a chegada do período chuvoso no Sertão, contemplando assim a volta do sertanejo para o seu lugar e Gonzaga utiliza também do pássaro e sua migração para reconhecer este momento. Algumas outras percepções como "Rios correndo, as cachoeira tão zoando / Terra moiada mato verde, que riqueza" deixam claro o conhecimento adquirido pela experiência vivida nestas condições naturais demonstrando uma relação de conhecimento do espaço e seus fenômenos, como o barulho das águas que é possível ouvir e a rápida mudança no aspecto visual da vegetação da caatinga.

É esta relação que nos permite compreender um sentido de lugar, pois o autor demonstra conhecer o espaço em que se está inserido devido as suas experiências pessoais que dialogam com o entorno. Além disso, fica claro na questão do lugar percebermos que apesar de ter abandonado o sertão em Asa Branca, ao primeiro sinal de melhor condição de vida o eu-lírico não titubeia em pensar em voltar ao seu espaço originário, pois sente que ali é onde deve estar. Também se nota a influência da relação com a personagem Rosinha, pois a relação com ela também está envolvida na questão do meio e a possibilidade de a safra não atrapalhar os planos de vida com ela. 
FIGURA 3: LETRA DE "NORTE NORDESTE ME VESTE”

\section{Norte Nordeste Me Veste \\ Rapadura}

\author{
[Intro] \\ O Nordeste é poesia \\ Deus quando fez o mundo \\ Fez tudo com primazia \\ Formando o céu e a Terra \\ Cobertos com fantasia \\ Para o Sul deu a riqueza \\ Para o Planalto a beleza \\ Pro Nordeste a poesia
}

\section{[Verso 1]}

Rasgo de leste a oeste como peste do sul ao sudeste

Sou rap agreste, Norte-Nordeste, epiderme veste

Arranco roupas das verdades poucas das imagens foscas

Partindo pratos e bocas com tapas mato essas moscas

Toma! Eu meto lacres com backs derramo frases ataques Atiro charques nas bases dos meus sotaques (Oxe!)

\section{$[\ldots]$}

Não vejo cabra da peste só carioca e paulista Só freestyleiro em Nordeste não querem ser repentistas

Rejeitam xilogravura o cordel que é literatura

\author{
Quem não tem cultura jamais vai saber o que é rapadura \\ Foram nossas mãos que levantaram os concretos os \\ prédios

\section{$[\ldots]$}

A cidade só existe por que viemos antes $\mathrm{Na}$ dor desses retirantes com suor e sangue imigrante

\section{$[\ldots]$}

[Refrão]

Elaboração: Autor, 2020.

Nessa faixa de Rapadura, podemos notar mais alguns aspectos sócio-culturais que da natureza, mas que estão ligados entre si. É possível perceber também algumas referências à história da região Nordeste, como se vê em "Atiro charques nas bases dos meus sotaques" e "Foram nossas mãos que levantaram os concretos e os prédios / [...] / A cidade só existe por que viemos antes", sendo primeira relacionada ao período em que o gado se desenvolvia como uma atividade econômica ainda no período colonial e a segunda nas migrações em que os nordestinos fizeram para outras regiões, buscando melhores condições de vida, para construir e erguer as cidades que vieram a ser grandes metrópoles por ser uma mão-de-obra barata, assim como afirma Xavier (2019a).

Em relação aos aspectos culturais percebe-se uma questão mais ligada a afirmação da identidade (e consequentemente ao lugar), ou pelo menos aos símbolos que fazem parte do imaginário do que é estar no sertão, como "Meto meu chapéu de palha sigo pra batalha" e 
"Rejeitam xilogravura o cordel que é literatura" em que se faz uma exaltação destas marcas consideradas tradicionais ao se pensar em Nordeste, que estariam relacionadas ao pertencer a região. Outro ponto relevante que se coloca em seus versos é um certo processo de apagamento, além de xenofobia, que acontece da região e sua cultura, fazendo com que os nordestinos tenham vergonha de admitirem suas origens ou entrem no padrão sudestino para que possam se sentir aceitos.

\section{A INTERVENÇÃO DIDÁTICA: PERCEPÇÕES E RESULTADOS}

A partir destas compreensões, associada à experiência de exercícios anteriores (resultantes de Estágios Supervisionados e de outros componentes curriculares voltados às práticas pedagógicas) de se trabalhar expressões artísticas ou mesmo ferramentas de comunicação, especialmente a música, como uma forma de se apreender conhecimentos geográficos sobre conceitos ou compreensão de espaços, se estruturou uma intervenção realizada em sala de aula.

O roteiro pensado para a intervenção foi simples, o primeiro passo foi a elaboração de um mapa mental com base em conhecimentos prévios sobre o Sertão Nordestino, desta forma a pesquisa foi bastante experimental, sendo marcada em um primeiro momento por um diagnóstico rápido construído a partir da discussão do que foi posto nos mapas. Na sequência foi feita uma breve exposição sobre os aspectos geográficos do Nordeste, seguida da reprodução das músicas que foram também discutidas e deram as bases para a reconstrução dos esquemas montados no primeiro momento.

A intervenção em classe foi realizada em duas turmas de $1^{\circ}$ ano do Ensino Médio durante a realização do Estágio Curricular Supervisionado IV, em Fortaleza, no ano de 2019 e a partir dela estruturam-se as percepções enquanto docente e as percepções dos estudantes que foram colhidas a partir de um questionário semiestruturado. 
FIGURA 4: FLUXOGRAMA DA REALIZAÇÃO DA INTERVENÇÃO

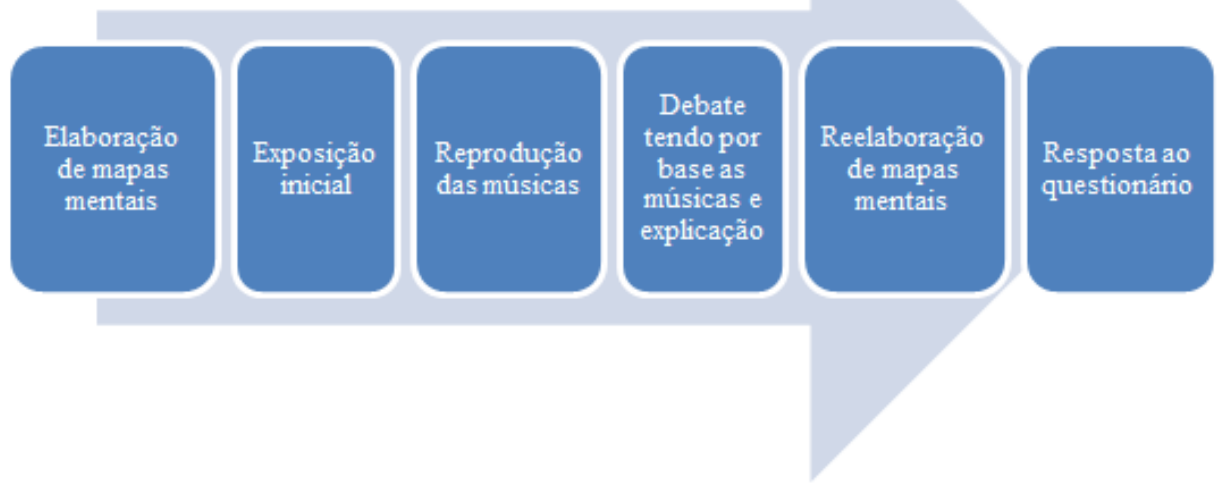

Elaboração: Autor, 2019.

A proposta de elaboração dos mapas mentais teve como base a teoria de Ausubel et al (2003) (apud MOREIRA, 1998) de aprendizagem significativa, o que juntamente ao questionário permitiria uma melhor análise da utilização da música como ferramenta em sala de aula e também que os estudantes observassem o processo de construção do próprio conhecimento, pois como afirmam Correia e Sá (2010, p. 43), com base em Okada e Santos (2005), em relação aos mapas mentais e a cartografia cognitiva, estes "demonstram que quanto mais o indivíduo consegue se expressar com formas que se aproximam de suas estruturas cognitivas, mais visível torna-se o processo de construção do conhecimento". Além disso, também houve produções artísticas (desenhos) dentro da temática, que apesar de fugirem do que foi pedido tem uma interessante demonstração de como se percebeu os conteúdos.

Uma observação importante é que durante a reprodução da música Asa Branca alguns estudantes cantaram juntos a música, demonstrando que considerada como tradicional ela ainda se faz presente no imaginário de muitos cearenses. Quando questionados sobre como tiveram contato afirmaram que é bastante reproduzida durante festas juninas, mas também que é colocada como um símbolo representativo da Região Nordeste e se sentem impelidos a conhecê-la. 


\section{FIGURA 5 - MAPA MENTAL CONSTRUÍDO POR ESTUDANTES}

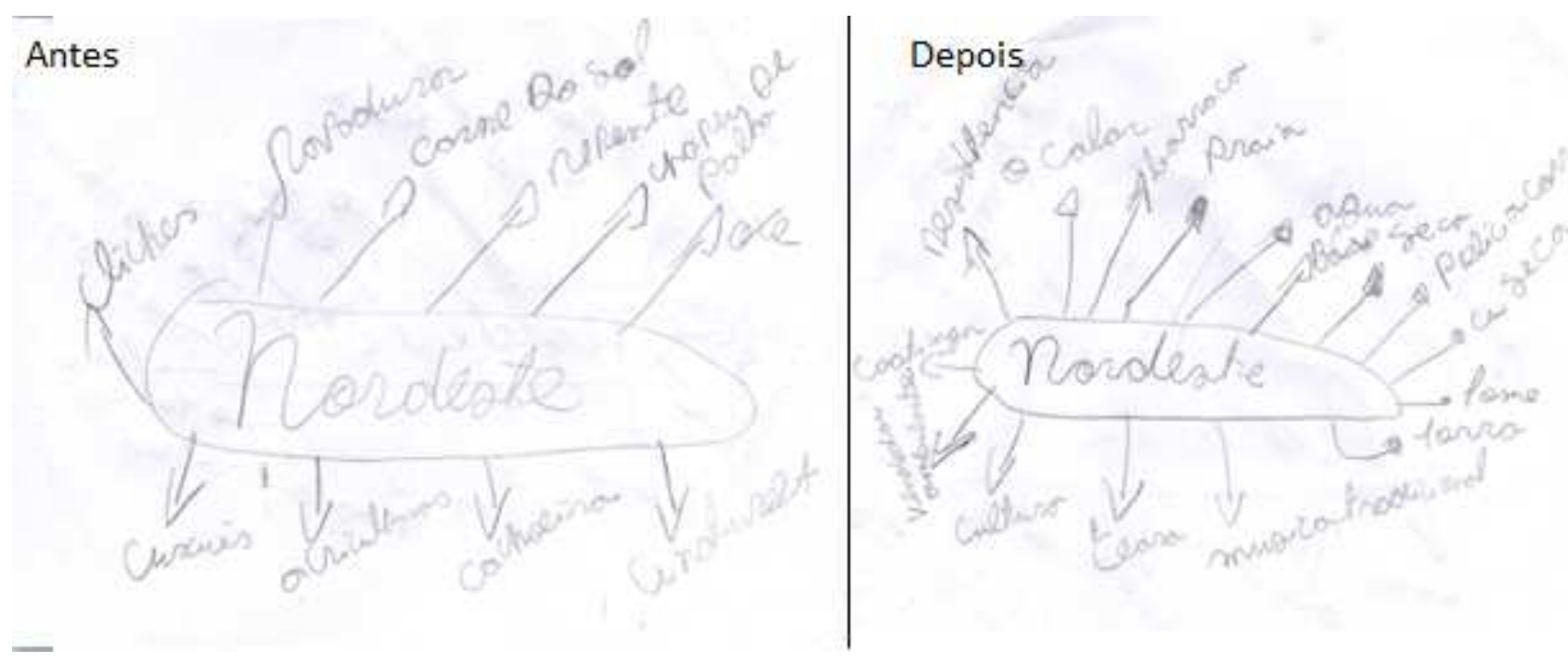

Fonte: Acervo do autor, 2019

Percebendo os mapas mentais de maneira crítica observa-se o formato radial/polarizado e por vezes informações generalizadas e isso pode estar relacionado com a maneira que os livros didáticos abordam os conteúdos associado a cobrança por resultados em exames de magnitude nacional, como o Enem (Xavier, 2019a). Além disso, nota-se, nos mapas da figura 5, o aumento da quantidade de informações que pôde ser inserida, reconhecendo alguns outros aspectos da região nordestina para além da seca como a questão da resiliência associada ainda a este aspecto, mas sendo um desdobramento da relação do homem com o espaço, também foi inserida a cultura, que de certa forma sintetiza algumas das palavras do "antes".

O questionário aplicado contou com 29 participações, 12 de uma turma e 17 de outra e teve como resultado a criação de alguns gráficos que serão explicitados a seguir juntamente com as respostas das questões abertas.

Quando perguntados sobre notarem a presença da Geografia no cotidiano $90 \%$ dos estudantes afirmaram que a percebiam, afirmando que a percebem "por conta das variações do tempo e as diversidades sobre o mundo" (A.B.P.M, 2019), e "principalmente com o tempo e as mudanças de estação" (C.S., 2019). Assim percebe-se que para alguns estudantes a relação do 
clima está diretamente relacionada a Geografia, bem como a compreensão sociedade no Nordeste perpassa também por esta temática.

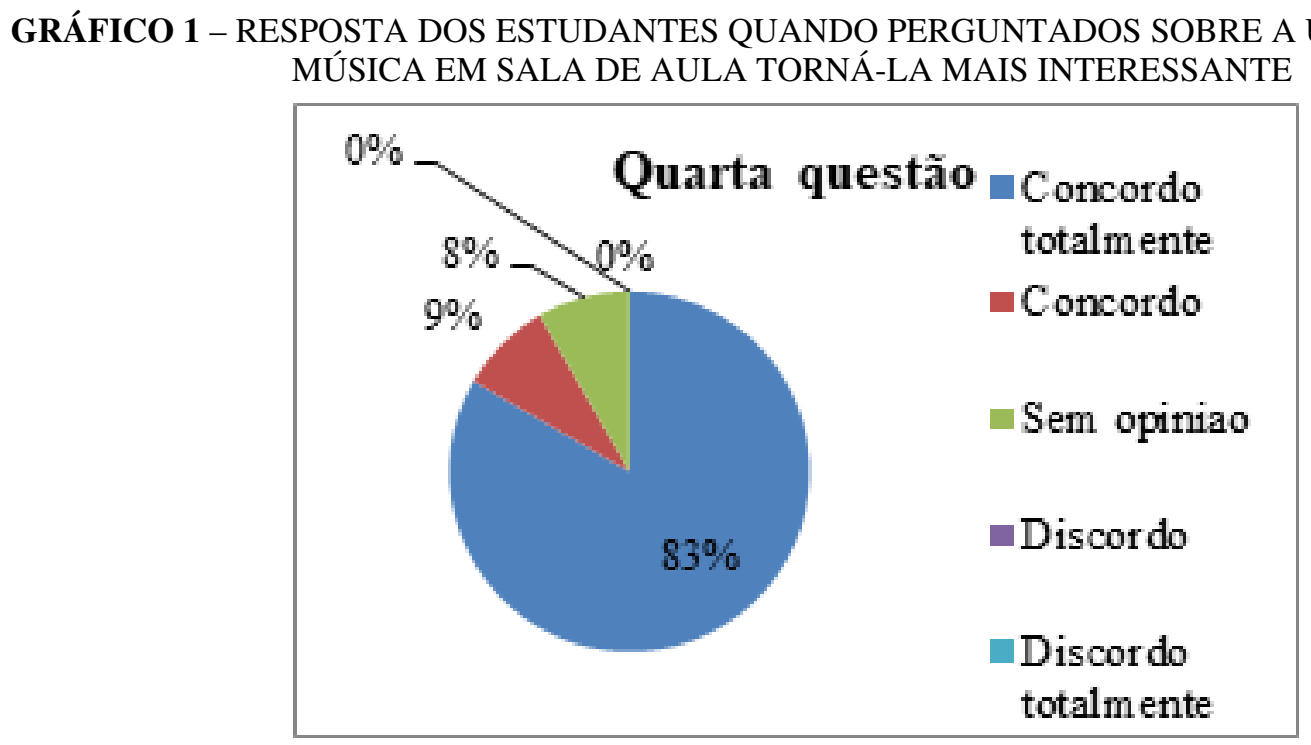

Elaboração: Autor, 2019

Com base nas respostas dos estudantes podemos ver que a música, enquanto ferramenta didática pode desenvolver um papel importante de atração e de compreensão do conteúdo. Foi comentado ainda que a música "tornou a aula mais atrativa e divertida" (A.V., 2019) e "facilitou o aprendizado, gostaria que fosse mais utilizado" (S.S., 2019), além de conseguirem construir relações com outras temáticas geográficas após um debate, comentando sobre algumas músicas sertanejas mais antigas.

Assim, é possível ver como a música se aproxima da realidade dos estudantes, se opondo ao modelo no qual, como posto por Kaercher (2011), os alunos não veem sentido. Assim surge a compreensão de se notar como a música, enquanto algo presente no dia-a-dia, pode ser um ponto inicial para se trabalhar questões de identidade em sala de aula como maneira de atrair os estudantes trabalhando algo que faça sentido para ele, bem como destacam Oliveira e Holgado (2016).

Além disso, ao pensar a questão da identificação podemos também observar a possibilidade apontada por Carney (2007) de a música ser capaz de implantar um sentido de orgulho para com os lugares. 

COMPREENSÃO DO CONTEÚDO.

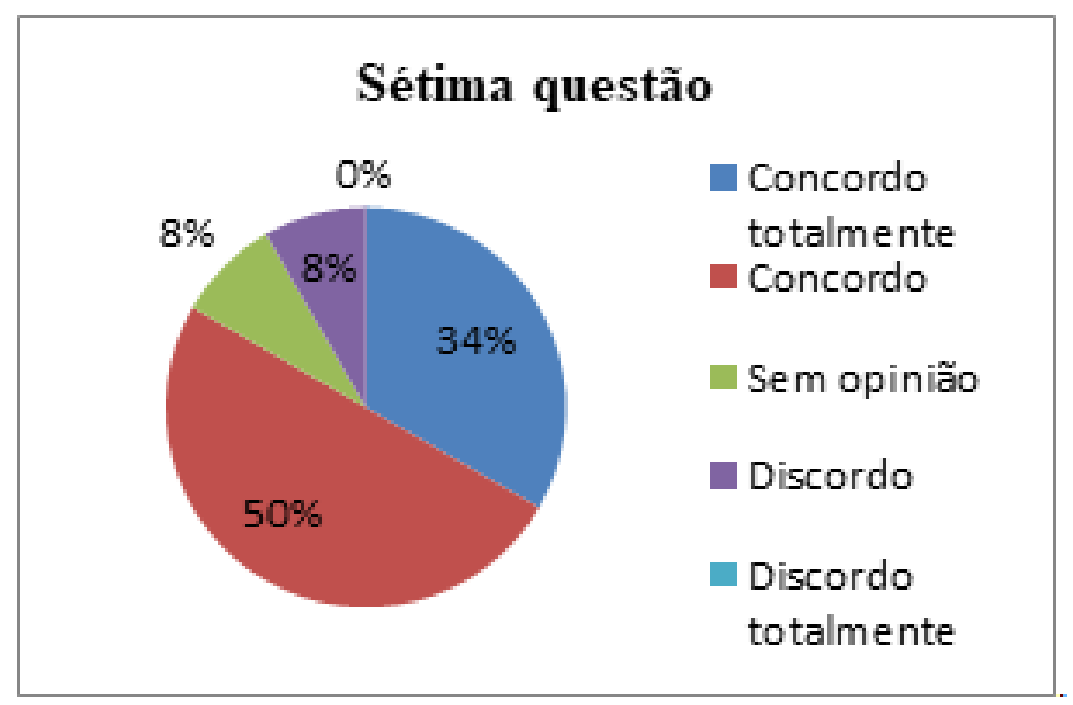

Elaboração: Autor, 2019

Apesar de uma discordância e uma ausência de opinião os estudantes consideraram que a utilização das músicas facilitou a compreensão dos conteúdos que foram ministrados durante a intervenção. Durante a reprodução das músicas foi possível observar o interesse de alguns estudantes e a motivação em construir as relações propostas, inclusive cobrando pela atenção dos colegas que estavam dispersos.

A partir destes dados e informações colhidas ao fim da intervenção é que se estruturam as considerações finais da pesquisa compreendendo a utilização da música como ferramenta em sala de aula, realização e reflexão docente e a possibilidade de compreender o espaço através da experienciação sonora.

Com estes resultados podemos perceber a possibilidade positiva da utilização da música como uma ferramenta ativa no ensino de geografia de maneira a atrair os estudantes e de facilitar a apreensão dos conteúdos. As respostas aos questionários aliados aos mapas mentais revelam que os 
estudantes puderam fazer parte da construção seu conhecimento sendo uma contribuição significativa para o processo de ensino-aprendizagem.

\section{CONSIDERAÇÕES FINAIS}

Os resultados positivos são também pessoais e comunitários, não só acadêmicos, pois percebendo o interesse dos estudantes é relevante considerar a aproximação que ocorre entre aluno e professor como cooperadores da comunidade escolar na construção do conhecimento. Necessitase também ressaltar que na utilização destas ferramentas alternativas é importante que seja feito um planejamento bastante organizado a fim de facilitar o processo e não fazer com que a atividade seja apenas uma proposição vazia.

Considerando o conteúdo relacionado podemos ainda notar a construção do Nordeste em nosso imaginário e na maneira em que as pessoas se aproximam e identificam com o espaço a partir das músicas. Fica claro também que a arte, neste caso a música, pode estar carregada de aspectos geográficos que permitem entender o mundo fora do espaço escolar.

É desta forma que se propõe uma compreensão crítica do espaço através das manifestações artísticas. Pensando especificamente no caso da relação Nordeste e música é possível pensar outras leituras das variadas realidades existentes na região através de algumas outras temáticas mais pontuais, como o desenvolvimento urbano em "Alô Campina Grande" cantada por Jackson do Pandeiro em que se nota o crescimento da cidade através da presença massiva de turistas e de mudanças na paisagem urbana que foram trazidas por um desenvolvimento voltado para estes, mas ao mesmo tempo se coloca que quem conheceu a cidade há algum tempo já não a reconhece mais a cidade justamente por conta destas alterações sofridas. Ou seja, há um pensamento crítico em torno da maneira como se deu o dito desenvolvimento, que pode vir a afetar até mesmo o pertencimento ao espaço.

Outro bom exemplo de concepção crítica e propositiva, encaixando-se com as ideias de análise libertárias, se demonstra na canção "Veia Nordestina" e "Condução" interpretadas pela cantora Mariana Aydar. Nestas a artista se apropria de uma musicalidade e compreensão da formação espacial do Sertão para pontuar a emancipação feminina em um meio que por muitas vezes é masculinizado, ou representado partir da visão do homem, se entendendo como sujeito ativo 
na construção da sociedade sertaneja, o que pode conferir-lhe uma identidade. Na segunda música inclusive se contesta o papel tradicional do homem de conduzir a parceira na dança, trazendo assim questionamentos sobre a ordem social padrão vigente.

\section{REFERÊNCIAS}

AUSUBEL, D.P. (2003). Aquisição e retenção de conhecimentos: uma perspectiva cognitiva. Lisboa: Plátano Edições Técnicas.

CARNEY, G. O. Música e lugar. In: CORRÊA, R. L.; ROSENDAHL, Z. (Orgs.). Literatura, música e espaço. Rio de Janeiro: EdUERJ, 2007. p. 123-150.

CORREIA, A. C. S.; SÁ, L. A. C. M. de. Mapas mentais na construção do conhecimento para geração de bases de dados espaciais. Boletim de Ciências Geodésicas, Curitiba, v. 16, n. 1, p. 3950, mar. 2010. Disponível em: https://revistas.ufpr.br/bcg/article/view/17243. Acesso em: 28 out. 2020.

ELIADE, M. Imagens e Símbolos. 768. ed. Lisboa: Arcadia.

FERREIRA, M. Como usar a música na sala de aula. 2. ed. São Paulo: Contexto, 2002. 238 p. Coleção como usar na sala de aula.

FREIRE, P. Pedagogia do Oprimido. São Paulo: Paz e Terra. Pp.57-76. 1996. Disponível em: $<$ https://edisciplinas.usp.br/pluginfile.php/610265/mod_resource/content/2/Texto6-Freire1parte.pdf>. Acesso em: 29. mar. 2020

KAERCHER, N. A. Das coisas sem Rosa uma delas é o Pessoa: as geografias do Manoel e do Nestor na busca do bom professor. In: TONINI, I. M. et al (Org.). $O$ ensino de Geografia e suas composições curriculares. Porto Alegre: Ed. Ufrgs, 2011. p. 205-220.

KROPOTKIN, P. What Geography Ought to Be. The Nineteenth Century, Londres, v. 18, 1885. Disponível em: http://dwardmac.pitzer.edu/anarchist_Archives/kropotkin/whatgeobe.html. Acesso em: 8 fev. 2020.

LIPIANSKY, E. M. A Pedagogia Libertária. Manaus: Editora Imaginária, 2007. 88 p.

LOWENTHAL, D. Geografia, experiência e imaginação: em direção a uma epistemologia geográfica. In: CHRISTOFOLETTI, A et al (Org.). Perspectivas da geografia. São Paulo: Difel, 1982. p. 103-141. 
MARANDOLA JUNIOR, E.; OLIVEIRA, L. de. Geograficidade e espacialidade na literatura. Geografia, Rio Claro, v. 34, n. 3, p.487-508, dez. 2009. Disponível em: <https://www.periodicos.rc.biblioteca.unesp.br/index.php/ageteo/article/view/4795/3949>. Acesso em: 11 fev. 2020.

MOREIRA, M. A. Mapas conceituais e aprendizagem significativa. Cadernos do Aplicação, Porto Alegre, v. 2, n. 11, p.143-156, 1998. Disponível em: 〈http://moreira.if.ufrgs.br/mapasport.pdf〉. Acesso em: 03 nov. 2019.

OKADA, A. L. P. e SANTOS, E. O. dos. Mapeando redes de informações com uso de software: uma experiência de pesquisa e docência em EAD online. Revista Digital de Tecnologia Educacional e Educação a Distância. Vol. 2 - n. 1. Outubro, 2005. ISSN 1808-1061. Disponível em: <http://www.pucsp.br/ tead/n2/pdf/artigo2.pdf>. Acesso em: 28 out 2020.

OLIVEIRA, A. U. de. Situação e tendência da geografia. In: OLIVEIRA, A. U. de et al. Para onde vai o ensino de geografia? 6. ed. São Paulo: Contexto, 1998. p. 123-124.

OLIVEIRA, C. D. M. de. Ensino de geografia e ciências da comunicação: por uma geografia mundana (geography and communication sciences: for an earthly geography). Mercator, Fortaleza, v. 3, n. 6, nov. 2008. ISSN 1984-2201. Disponível em: <http://www.mercator.ufc.br/mercator/article/view/127>. Acesso em: 22 oct. 2020.

OLIVEIRA, V. H. N.; HOLGADO, F. L. Conhecendo novos sons, novos espaços: A música como elemento didático para as aulas de Geografia. In: DOZENA, A. (Org.). Geografia e Música: Diálogos. Natal: Edufrn, 2016. p. 84-103.

PIZZOTI, A. M. Geografia e música: aproximações e possibilidades de diálogo. In: DOZENA, A. Geografia e Música: Diálogos. Diálogos. Natal: Edufrn, 2016. Cap. 4. p. 104-132. Disponível em:

https://repositorio.ufrn.br/jspui/bitstream/123456789/21381/1/Geografia\%20e\%20M\%C3\%BAsica \%20\%28livro\%20digital\%29.pdf. Acesso em: 13 mar. 2020.

RECLUS, É. L'Homme et la Terre. Paris: Librairie Universelle, 1905-1908. 6 v. O endereço online pode variar de acordo com o volume. Disponível em: <https://gallica.bnf.fr/ark:/12148/bpt6k65596472.r=1\%27homme\%20et\%20la\%20terre?rk=85837;2 >. Acesso em: $10 \mathrm{dez} .2019$.

RELPH, E. As bases fenomenológicas da Geografia. Geografia, Rio Claro, v. 4, n. 7, p.1-25, abr. 1979. Quadrimestral.

SILVA, R. S. da. A Importância da Música nas Aulas de Geografia: Práticas e métodos diferenciados no uso da música como metodologia de ensino nas aulas de Geografia. 2015. $45 \mathrm{f}$. TCC (Graduação) - Curso de Geografia, Centro de Formação de Professores da Universidade Federal de Campina Grande, Universidade Federal de Campina Grande, Cajazeiras, 2015. 
Disponível

em: <http://www.cfp.ufcg.edu.br/geo/monografias/RENAGILA\%20SOARES\%20DA\%20SILVA.pdf>. Acesso em: 02 out. 2020.

SOUZA, M. L. de. Quando o trunfo se revela um fardo: reexaminando os percalços de um campo disciplinar que se pretendeu uma ponte entre o conhecimento da natureza e o da sociedade. Geousp - Espaço e Tempo, São Paulo, v. 22, n. 2, p.274-308, 28 ago. 2018. Disponível em: <http://www.revistas.usp.br/geousp/article/view/147381/148238>. Acesso em: 02 out. 2020.

TUAN, Y. Espaço e Lugar: A perspectiva da experiência. São Paulo: Difel, 1983. Disponível em: $<$ http://www.artevisualensino.com.br/index.php/textos/send/16-textos/481-yi-fu-tuan--espaco-elugar-a-perspectiva-da-experiencia>. Acesso em: 20 set. 2020.

XAVIER, L. D. F. (Re)conhecendo o Sertão Através do Som: A utilização da música como metodologia de Ensino de Geografia. 2019. 44 f. TCC (Graduação) - Curso de Geografia, Departamento de Geografia, Universidade Federal do Ceará, Fortaleza, 2019. Disponível em: <http://www.repositorio.ufc.br/handle/riufc/50906>. Acesso em: 17 fev. 2020.

XAVIER, L. D. F. O sentido político e social do rap em fortaleza: construindo afetos, ocupando espaços e (re)construindo percepções. Revista Oppala, Fortaleza, v. 2, n. 2, p.10-10, dez. 2019. Disponível em: <http://www.lege.ufc.br/images/stories/arquivos/revista\%20_oppala_n2_vf.pdf?fbclid=IwAR2sNy SuNkvSiot8-9U14_1sNYSaPVGKJ4mkuP0664ncDc2Yt-_s5S1tlZE>. Acesso em: 17 fev. 2020 